\title{
Simultaneous detection of Salmonella spp., Salmonella Typhi and Salmonella Typhimurium in sliced fruits using multiplex PCR.
}

\begin{abstract}
This study aimed to determine the prevalence and quantity of Salmonella spp., Salmonella Typhi and Salmonella Typhimurium in sliced fruits from hawker stalls and hypermarkets in Malaysia. Analysis was carried out using the most probable number (MPN) - multiplex polymerase chain reaction (PCR) method. The prevalence of Salmonella spp., Salmonella Typhi and Salmonella Typhimurium in 210 samples of sliced fruits examined were $23.3 \%$, $7.6 \%$ and $3.8 \%$, respectively with estimated quantity varying from 0 to $19 \mathrm{MPN} / \mathrm{g}$. This study urged the authority to look into the biosafety of sliced fruits in Malaysia.
\end{abstract}

Keyword: Salmonella; Sliced fruits; Multiplex PCR; Simultaneous detection. 